Getting to the heart of the matter: An ethnography of emotions and emotion regulation in cardiac rehabilitation

Samantha J. Meredith, Christopher R. D. Wagstaff \& Matt Dicks University of Portsmouth, UK

Accepted 12/11/18 for publication in Qualitative Research in Sport, Exercise and Health

Samantha J. Meredith, Christopher R. D. Wagstaff \& Matt Dick, Department of Sport and Exercise Science, University of Portsmouth, United Kingdom. Correspondence concerning this article should be addressed to Christopher R. D. Wagstaff, Department of Sport and Exercise Science, University of Portsmouth, Spinnaker Building, Cambridge Road, Portsmouth PO1 2ER, United Kingdom. E-mail: chris.wagstaff@port.ac.uk 


\begin{abstract}
Considering the detrimental impact of emotional suffering on patient recovery (e.g., increased mortality rates), a key component in rehabilitation settings should be the promotion of psychosocial health. Research has shown cardiac rehabilitation (CR) to decrease anxiety and depression, enhance emotional well-being, and reduce the deleterious effects of negative emotions on prognosis. Nevertheless, limited attention has been given to heart disease as a lived experience and the presence of the patient's voice in $\mathrm{CR}$ is negligible. Using an ethnographic approach, the aim of the current research was to provide a penetrative insight into the social and psychological environment of a CR setting in the United Kingdom. Three main methods were used to collect data over a 12-month period, including participant observation (225 hours), informal and formal interviews, and a reflexive diary. Thematic analysis was used to generate patterns (themes) in the data. Following thematic development, ethnographic creative non-fiction was adopted to fashion non-fictional stories grounded in real events and patients' lived experiences. Three composite narratives illustrated the emotional intensity of recovering from a cardiac event, and highlighted the value of CR to aid patients with reskilling and emotional support. In discussing our data, we emphasize the potential value of emotional intelligent care provision, and the creation of an environment that encourages emotional disclosure. We conclude with a discussion of the value of narrative medicine as a pedagogical tool for CR staff and patients.
\end{abstract}

Keywords: cardiac rehabilitation; emotion regulation; emotions; referral; narrative 


\section{Getting to the heart of the matter: An ethnography of emotions and emotion regulation in cardiac rehabilitation}

A cardiac event is a traumatic, life changing experience, associated with physical incapacities, and significant emotional suffering (e.g., Wheatley, 2006). According to the British Heart Foundation (BHF) (2018), cardiovascular disease (CVD) causes more than a quarter (26 per cent) of all deaths in the United Kingdom, accounting for over 150,000 deaths annually. Survival rates following acute cardiac episodes have improved significantly in recent decades, owing to advances in acute coronary care (see Byrne, Stone, Ormiston \& Kastrati, 2017). Nevertheless, patients often contend with ongoing symptoms, medicinal side effects and hospital readmission (see Van Stel, Busschbach, Hunink, \& Buskens, 2012). Consequential to the nature of CVD, patients often experience an array of psychosocial difficulties that adversely affect their recovery and quality of life, including anxiety, depression, disruptions in identity, and perceived loss of control (e.g., Thombs et al., 2006). Moreover, of growing concern in rehabilitative settings is the incidence of negative psychological states and their role in adherence to rehabilitation, uptake of health behaviours, and disease prognosis (e.g., Michie, O’Connor, Bath, Giles, \& Earll, 2005). That is, there is a robust association between the diagnosis of acute coronary syndrome and the occurrence of psychopathology, such as depression, anxiety and panic attacks (e.g., Watkins et al., 2013). Such incidence of psychopathology has been linked to increased risk of mortality, increased healthcare costs, and reduced long-term quality of life (Hosseini, Ghaemian, Mehdizadeh \& Ashraf, 2014).

Considering the detrimental impact of emotional suffering on patient's recovery, a key component in rehabilitative settings should be the promotion of psychosocial health (BACPR, 2017). Typically, following acute treatment of CVD (e.g., percutaneous coronary intervention), patients are referred to cardiac rehabilitation (CR) to facilitate both physical and psychological recovery, as well as an absolute risk reduction in cardiovascular mortality (Anderson et al., 2016). An established evidence base supports the effectiveness of CR, demonstrating improvements in 
cardiorespiratory fitness, reduction in all-cause mortality, reduction in cardiac mortality, reduction of hospital readmission, improved quality of life, and enhanced functional capacity (e.g., Yohannes, Doherty, Bundy, \& Yalfani, 2010). Nevertheless, a recent clinical review of CR (Dalal, Doherty, \& Taylor, 2015) warned that not: Association of Cardiac Prevention and Rehabilitation (BACPR) standards. Indeed, data from the national audit of cardiac rehabilitation (BHF, 2017) indicated that there is considerable variation in the quality of regional service delivery, highlighting the need for research and development within CR. In line with current calls for improved mental health services in the NHS (Mental Health Task Force, 2016), and considering the implications of effective emotion regulation on recovery (see de Ridder, Geenen, Kuijer, \& van Middendorp, 2008), an important research direction in CR concerns the emotional experiences of patients, and the way in which CR services enhance psychosocial support and recovery.

Emotional dimensions of living with a chronic health condition are frequently overlooked when medical care is considered (see Turner \& Kelly, 2000), and although psychological interventions are encouraged in CR (e.g., Linden, 2000), there is often poor access to psychological services for patients (e.g., Mental Health Task Force, 2016). Indeed, researchers have argued that CR can help decrease anxiety and depression, enhance emotional well-being, and reduce the deleterious effects of negative emotions on prognosis (e.g., Mitchie et al., 2005). Moreover, while researchers have noted the importance of creating interventions that foster positive emotions to overcome symptoms of depression and negative affect in CR (e.g., Bedi \& Brown, 2005), research on emotions in CR are largely based on questionnaire data (e.g., Bedi \& Brown, 2005; Hosseini et al., 2014), and fail to illuminate individual's subjective, reflexive experiential, narratives of emotional issues in CR (e.g., Simony, Dreyer, Pedersen \& Birkelund, 2015).

Crossley, Nicolson, and Owens (2001) argued that 'mainstream' health psychology objectifies and depersonalizes people's experiences of healthcare to pursue a goal-oriented 
'technical' programme akin to medical science and practice, providing a simplistic response to the complex reality of human lives. In response, researchers have looked to the qualitative paradigm to provide rich, in depth insight, and emotional clarity of what patients and staff undergo during everyday activities in CR (e.g., Simony et al., 2015). For instance, Wheatley (2006) conducted an ethnography in Northern California, USA, enabling the study of social life in a natural setting. A key aspect of Wheatley's work was the observation that individuals living with illness remake the body, self and social world through a process of reskilling after acute episodes of cardiac disease. This reskilling involved ongoing efforts to interpret risks and remake the body, to redefine and reinvent the self, and to rearrange social relations and routines (Wheatley, 2006). To elaborate, Wheatley discussed the onset of cardiac symptoms as a disruption in bodily and emotional states of being and knowing, and the interpretive work people perform in analysing conditions of their own embodiment. Wheatley highlighted peoples socially negotiated dimensions of reskilling, noting how social relations can constrain or enable reskilling, rather than being determined by health knowledge or individual choices of patients. Moreover, despite clients expressing different degrees of trust in expert claims about risk, and showing different styles of reskilling, Wheatley suggested that CR enabled body, self, and social transformations, improving 'care of the self'. Notably, Wheatley suggested that reskilling is never fully finished and is an ongoing requirement of living with and inhabiting a troublesome and unpredictable body.

In addition to ethnographic approaches, scholars have highlighted narrative medicine and illness stories, as an effective method to explore the characteristic nature of emotions with subjectivity, meaning and reflexivity (e.g., Charon, 2006). Narrative medicine creates rich qualitative stories that can bridge patient's and health professional's perspectives, improving therapeutic relationships and communication. Consequently, health professionals can improve their understanding of what patients endure with CVD to provide effective care, and patients can reshape their experiences of illness, promoting self-healing. For example, Frank (2013) emphasized the importance of sharing experiential accounts of illness and having others (e.g., 
health professionals) listen to, or 'bear witness' to those experiences. Illness stories might take several different narrative forms, including restitution narratives (i.e., returning to one's previous state of health), chaos narratives (i.e., all life events are contingent and no one is in control), and quest narratives (i.e., illness as a spiritual journey).

While there have been important objective insights into the emotions experienced and coping strategies reported within CR (e.g., Mitchie et al., 2005), negligible attention has been given to heart disease as a lived experience. Hence, qualitative inquiries, including ethnography and narrative medicine could provide a rich and hitherto elided insight into patient and staff experiences within CR. Using ethnographic creative non-fiction, the aim of the current research was to provide a penetrative insight into the social and psychological environment in a United Kingdom (UK) CR setting, with a specific focus on affective and behavioural phenomena. Participant's stories were presented in a composite narrative to further the readers' knowledge and understanding of a UK CR culture. It is hoped this narrative will provide pedagogical value to CR staff and patients.

\section{Methods}

\section{Methodology}

The current study used ethnographic creative non-fiction underpinned by ontological relativism (i.e., knowledge is relative to differences in perception, and is mind-dependent) and epistemological constructivism (i.e., knowledge is constructed and subjective), to deliver a detailed understanding of emotions and emotion regulation within a UK CR service (see Atkinson \& Pugsley, 2005; Smith, McGannon, \& Williams, 2015). Ethnographic principles and techniques were adopted to collect in depth qualitative data that was historically and situationally bound (see Krane \& Baird, 2005). Ethnography refers to the study of social interactions, behaviours, and perceptions that occur within groups, teams, organisations, and communities, providing rich, holistic insights into people's views and actions (Reeves, Kuper \& Hodges, 2008). Ethnographic results were communicated with creative non-fiction, which allowed empirical data to be 
showcased with emotionally vibrant narratives (Smith et al., 2015). The ethnographer was a clinical exercise instructor who shared a common cultural background with the CR staff, and had 10 years of experience working within rehabilitative settings. Employed by the organization, the ethnographer had an insider status, adopting the role of participant-observer, in which they directly worked alongside staff and patients. Good working relations and rapport with staff, volunteers, and patients afforded the ethnographer access to situations and conversations, perhaps not available for someone considered an 'outsider' (see Hammersley \& Atkinson, 2007). In line with the philosophical underpinnings of the current study, the ethnographer's beliefs and experiences in rehabilitation guided behavioural interpretations and analyses (Smith et al., 2015). The study was approved by the National Health Service Health Research Authority.

\section{Participants and CR setting}

The study was undertaken for 12 months (2017-2018) in a CR service which functioned as one of several sites operating across a regional hospital Trust in England. This service was selected as they had received certification by the BACPR and the NACR, which determined whether the service had met minimum national standards. The CR service took place every Monday and Wednesday evening, $17.30-20.00$, and consisted of an hour group exercise session, followed by 45 minutes for pre-assessments with newly referred patients. The service had been running for 15 years, led by a specialist cardiac nurse, and supported by a physiotherapist, a second cardiac nurse and a clinical exercise instructor, as well as 6 volunteers. Patients referred to the service generally had acute coronary syndrome (e.g., angina, myocardial infarction), heart failure, arrhythmia, or valve replacements, and often had co-morbidities, such as diabetes mellitus, stroke, respiratory disease, and osteoarthritis.

\section{Data collection}

The research began with a broad question, examining the emotions experienced during CR, and the way in which staff and patients regulated emotions. A period of 2 months for familiarisation was completed to immerse the researcher within the research process, allowing the 
ethnographer to engage the social setting steadily and with critical reflexivity (see Hammersley \& Atkinson, 2007). As the research developed, formative thoughts about issues of importance relating to emotions and regulation strategies were focussed on, facilitating an iterative process between data collection, analysis, and interpretation (Silk, 2005).

Three main methods were used to collect data, including participant observation (225 hours), informal and formal interviews, and a reflexive diary. Participant observation involved 90 visits to the CR sessions over a period of 12 months with each visit lasting $2 \frac{1}{2}$ hours. The ethnographer observed the set-up of the gym, arrival of patients, patient conversations preexercise, exercise circuits, post-exercise assessments, patient pre-assessments, and closing/tidying of the gym. Participant observation data comprised field notes recorded after each CR session. Participant observations allowed verbal and non-verbal behaviour to be captured, providing a moving picture of patient's journeys through CR, exploring how cardiac conditions, and how emotions unfolded over time and influenced daily life from a rehabilitation perspective (lens). Casual conversations with participants were also recorded within the field notes to supplement observational records and analyses. In line with the philosophical underpinnings of this study, the ethnographer's experiences as a clinical exercise instructor and previous knowledge of emotion theory and concepts influenced the interpretation of observations. Therefore, alongside field notes, the first author also kept a reflexive diary recording their own experiences and feelings as an instructor which informed the development of the data, and the interaction between their roles as a researcher and participant-observer. A reflexive diary was especially important to consider the first author's position in data collection and interpretation and how the first author's own emotions, experiences and assumptions might have influenced the study (Gilmore \& Kenny, 2015). The field notes and reflexive diary consisted a total of 133 pages of single-spaced text. An example copy of the field notes is available on request from the corresponding author.

Interviewing began once themes in the observation data emerged. Numerous informal interviews and conversations took place over the course of the ethnography. To supplement these 
interactions 10 formal interviews were conducted to further elucidate the lived experiences of several key actors within the CR context. The sampling was purposeful, interviewing patients $(n=$ $4)$, staff $(n=3)$ and volunteers $(n=3)$ to explore interesting ideas in the data and ceasing sampling when no further new themes were emerging in the data (i.e., saturation). Interviews allowed the researcher to gain different perceptions, and gave meanings to observations. Interviews included unstructured interviews (to gain descriptive information), and semi-structured interviews (to probe and gain richer information) around the topics of emotion and emotion regulation and participant's experiences within CR. A three-part guide was used for semi-structured interviews, the first section was designed to elucidate the participants background story (e.g., "could you describe your cardiac event?"), the second section aimed to explore participant's emotional experiences and regulation patterns (e.g., "could you describe your emotional journey from your event until now?"), and the third section explored participants' experiences in the CR setting (e.g., "how would you describe the atmosphere at CR?”). The guide was adapted for each participant, and over the course of the ethnography, developing questions to give meaning to specific observations. The mean duration of interviews was 42.86 minutes $(S D=16.67)$. Participant interviews included 2 female cardiac nurses (aged 34 and 58), 1 female physiotherapist (age 29), 2 male patients (aged 46 and 59), 2 female patients (aged 59 and 70), 2 female volunteers (aged 72 and 82), and 1 male volunteer (age 68).

\section{Data analysis and representation}

The data were analysed in two separate stages. The first stage used thematic analysis to provide ongoing critical reflections of field notes (i.e., observations), reflexive diaries, and interview transcripts. Thematic analysis allowed for the development of patterns (themes) in the data (Braun \& Clarke, 2006), providing insight into staff and patient experiences within CR, and their associated emotions. Following Braun and Clarke's (2006) guidance for thematic analysis, the data were organized into codes, first-level and second-level sub-themes, and overarching themes. As a result of this process, the first author, with reflexive and discursive help from the 
research team, discovered the "what's", (i.e., the themes), the "how's" (i.e., the "enacting" of emotion regulation) and "why's" (i.e., the effects of emotions on health behaviours) of the participant accounts (Cavallerio, Wadey, \& Wagstaff, 2016). Once themes in the data were developed and critically reviewed within the research team, the second stage, a creative analytical process (CAP), was adopted to represent the ethnographic data (see Smith \& Sparkes, 2009).

Using ethnographic creative non-fiction (Smith et al., 2015), the empirical evidence developed through thematic analysis was used to fashion non-fictional stories that were grounded in real events and peoples' lived experiences. Techniques of fiction were adopted for its emotional vibrancy and to represent qualitative findings in a way that could translate to multiple audiences (e.g., Smith, 2013). Firstly, the ethnographer acted as a 'story analyst', using thematic analyses to theoretically interpret empirical data, and consider practical points for each narrative that could represent and show the complex relationships, emotions, and behaviours in CR. Compelling quotations and observations for each theme were selected to enable the development of narratives (e.g., Hings, Wagstaff, Anderson, Gilmore, \& Thelwell, 2018). Next, the ethnographer took on a 'story teller' role, re-casting the data to produce narratives steered by Smith and colleagues (2015) ethnographic creative non-fiction guide. Specifically, when developing the narratives, the ethnographer considered delivering a vivid description of events and emotions through rich creative writing, using words to evoke and vividly reveal lived meanings, and using dialogue to present emotional vibrancy through conversations. The author sought truthfulness in the development of narratives by being faithful to the experiences and the emotions described in the empirical data (i.e., field notes, reflexive diaries, interviews), and aimed to evoke a sense of embodiment by detailing the characters' body in motion in an emotionally expressive manner. Each narrative included important complex characters informed by key findings in the thematic analysis to meet the purpose of the study (i.e., an exploration of emotions and emotion regulation). A cohesive plot was developed, connecting points across time, and considering where and when to locate people in the CR setting. The narratives drew on felt experiences and listened to the many 
voices heard throughout the ethnography, including direct quotations from interviews. Each narrative was edited and revised with reflexive support from the research team. Following this process, three composite narratives were produced to represent the data through providing a mix of experiences amalgamated into a single account (see Spalding \& Phillips, 2007). On completion, these narratives were shown to participants to ensure they resonated with their experiences in CR.

To judge the quality of the study, the researcher considered guidelines underpinned by the epistemological and ontological assumptions of the current qualitative research, highlighting the authenticity of the work rather than positivistic assumptions of validity and reliability (see Smith \& McGannon, 2018). Following guidelines from Sparkes and Douglas' (2007), and Smith et al. (2015), the rigor of the ethnographic creative non-fiction was judged by whether the narratives: 1) provided the reader with a meaningful expression of reality and a sincere picture of the CR experience, 2) were plausible and credible in the way they were presented, 3) showed empathy and respect for all participants, 4) advanced understanding of emotions in CR, 5) had aesthetic merit, and 6) resonated with the readers' experience, and in turn, stimulated dialogue and reflection and a meaningful contribution to research and practice.

\section{Results}

The narratives that follow reflect the participants' stories and experiences in the cardiac referral service. The narratives showcase the emotional experience of the patients and are supplemented with participants' own voices using direct quotations.

\section{Surviving anxiety: "I mean physically I am fine, but mentally I am struggling." The sweat}

glistened on George's forehead. A bead trickled down his sallow face and rested in his stubble. He glanced down nervously at his pulse rate, as he stepped slowly from side to side. The hospital gym was busy tonight. There was a friendly buzz in the air, and a gentle rumble of chatter, as patients shifted from one exercise to the next. But George seemed removed from the rest of the group, like he was casting his own gloomy shadow. He was only 54, but the heart attack added an extra 20 years. He stooped and shuffled away in the corner of the gym and cautiously lifted his knees the 
least amount required to execute the exercise. Panting. A little out of breath, very far out of his comfort zone. Every movement was careful, considered, as if he was walking on thin ice. He glanced again at his heart rate. Transfixed by the monitor. Obsessed with every sensation in his diminished body. Searching diligently for vindication of his feelings, looking for the exact thing he dreaded; a spike in heart rate. Suddenly George's eyes widened, "130!" he shouted, panicking. In an instant, he burst out of the corner and rushed toward the gym exit in a state of terror. His face was awash with dread, and he breathed quickly, sliding past the other patients. The physio tried to intercept and engage him with a caring, outstretched, hand, but George powered through and pushed out of the exit. He was met by one of the nurses; a strong matriarch type. Seen it all. Tough exterior, but empathetic. She stood in the doorway. George clutched his chest tightly, "look at this!" he gasped pointing to the heart rate displayed on the monitor. The nurse calmly scanned his wrist, then looked up into George's horrified eyes, "it's okay, your heart rate is fine!" But George wasn't convinced. His breathing had become faster and shallow. He looked pale. The nurse read his expression and coolly led him into another room.

George sat tensely in the chair, clutching the sides with white-knuckled hands. The nurse moved steadily and knelt next to him, lowering herself to the same height as him. His anxiety was unmistakeable. It clung to him and spilled out into the quiet waiting room. "Listen George, your heart rate is fine, and you are fine. Just try to relax", the nurse placed a warm hand on the back of his rigid knuckles. His gaze shifted and his focus came back to the room and centred on the reassuring nurse's eyes. The nurse smiled, and spoke softly, “tell me what's going on?” George shuffled uncomfortably in his seat and sighed, “It's just after you've had a heart attack and someone asks you to do an exercise, you think 'SHIT I can't do that!'” he blurted with a frustrated sigh. The nurse nodded, her head turned slightly to the side in an empathetic manner. George continued, "It's all in the mind... you know, your confidence to do things." His mouth quivered and he dropped his head, 'It was such a shock. I didn't think it would ever happen to me. It's still a shock." George is a young, successful businessman and has led an active life. "I never used to be 
like this; I wasn't... an anxious person. I have always been tip top. I watched what I ate, and I exercised. So, it has shown a whole new side to me that I don't like very much.” The nurse nodded in understanding. She didn't disrupt George; she was letting him tell his story. Letting him vent. "I haven't forgiven my body for letting me down and I feel very vulnerable. I am just really aware of my heart rate and the feelings in my body. It's scary!"

Six weeks later. A familiar smell of sweat, and antibacterial wipes wafted in the air, as the patients filed in line to have their heart rate monitors fitted. "Brace yourself, this is going to be cold!" a volunteer smiled as she pressed a monitor to a patient's chest and wrapped the strap around their back. He winced and chuckled, “you enjoy torturing us, don't you?!” The volunteer laughed and patted him on the back, before the patient ambled off giggling to find a chair. The door suddenly swung open and the physio stepped over the threshold smiling. "Evening all!" she glowed, nodding to each patient as she made her way to the table at the front of the room. Her energy and warmth was tangible, and it swept through the atmosphere, rippling across the room. She joined one of the nurses, flicking through and organizing the patients' clinical notes. "Is George in tonight?" the physio asked, holding his paperwork up to the light, "he seems to be doing a lot better". "Yes, and we are keeping him on for a few extra sessions", the nurse leant on the table, hand on hip. "He was just very anxious, and is still very fearful of any slight changes to his body", the nurse continued. "I think keeping him on a bit longer will do wonders for his confidence. He just seems to need more reassurance compared to some other patients. I don't think he is mentally ready to leave yet."

George pushed hard on the pedals. His face was flushed pink, pearly beads of sweat shining in the artificial light. Each leg contraction looked controlled and meaningful. Looking at him now I could visibly see a transformation; once a chaotic retracted mind, he now appeared to be moving with a renewed determination. "George, you have really turned a corner!" the physio grinned. "Yeah, I'm feeling good at this moment", George panted and slowed his cycling cadence to speak. "I just had no idea that anxiety could be so crippling. I mean physically I am fine, but 
mentally I am struggling. I can't believe how much the anxiety changes you, even to the extent that I can actually feel tingling down my arms!" he traced a finger down a forearm with a surprised expression. "Well you look a lot better, how are you coping now?" the physio leaned in closer and placed a hand on the front of the bike. "Yeah, I'm a lot better. I was petrified when I first came in. I don't normally get scared. Something like this changes your outlook on life. I was so apprehensive, you know, I was so aware of my heart rate and how my body felt.", George breathed. "It's up here", he pointed to his forehead and smirked. "But I've learnt to control it. I just try and ignore my heart rate and not worry because when I worry and I'm apprehensive it gets worse, it [heart rate] goes up. So, I just think 'STOP, it's fine!'” The physio nodded enthusiastically, “ah cool, I'm pleased you are coping, and you are working a lot harder in the exercises now", she praised. George smiled. He looked so different when he smiled. Far from the tired, sallow, shuffling person that appeared at his first session. "My confidence has increased. I know if anything untoward happens here I will be okay. I know that you guys have the expertise and the knowledge, so I feel safe in this place.” He paused and slid off the bike seat, facing the physio, "I was fearful, but now I feel like I am managing better. You know, you have a heart attack and they get you in and put a stent in you and it happens so quick, and then you're at home again. Then they ask you to exercise, and you think, 'are you CRAZY?! I've just had a heart attack!' But it's a supportive environment here, this has been so useful."

George sat quietly reading his certificate proudly, 'Congratulations on completing cardiac rehabilitation'. He smiled. The nurse had just finished George's final review, thus concluding his journey through the service. His progress was visible; he had evolved from a chaotic and tumultuous state and had found a path to composure and his new sense of 'normal'. He added: I wanted something positive that I could, in a safe environment, use to reinforce the fact that I was heading in the right direction. I was getting better, and I wanted something to show me that I would have a 'normal' life again. Rehab has really helped with this, and the other people that are in here. It's just nice to have a group of people with a shared 
experience, that can have a laugh and a joke and have a chat about the issues and what drugs you're taking and how horrible they are!

He laughed loudly. The nurse grinned and nodded. 'But I don't feel fixed, even now I don’t feel fixed completely because of the digestive issues I've got and all the side effects from the drugs that I take; now it's that I'm struggling with", George's smile dissipated and a frown appeared. The nurse listened, tilting her head to the side and nodding occasionally, sufficiently. "It's a permanent reminder that things aren't perfect, I'm not perfect, which I always thought I was", George continued as he shifted in his chair. "I don't want to be reminded day-in, day-out that I've had a problem, and could still have problems in the future. I think that's one of the things that I struggle with. Because I don't feel healed all the while that I am being reminded.” There was a moment of silence, the nurse leant forward, "and how are you coping with these feelings?"

George shrugged, "a lot better. It's the fear of dying, but I visualise my fear now. I give it a name, a colour, a shape, and then visualise putting it in a box." The nurse bowed her head in understanding. Despite George's recovery he appeared to be left scarred by the traumatic experience of his cardiac event. The nurse seemed to pick up on this, she was like a weathervane, sensing a storm of emotions. Her posture and manner changed, she adapted to support the patient. She was calm and compassionate, but also knowledgeable and strong; someone to lean on. George continued, "I've learnt how to control it. I understand that fear is there for a reason, it's the reason I got blue lighted into hospital, and for a good reason, it allowed me to seek treatment. I just didn't know how to control it, and manage it so that it wasn't detrimental to my health. It got to the point where my anxiety wasn't saving me anymore; it was actually putting me in a dark place - not killing me, but definitely stopping me live", he shared. "But I am learning to accept my new 'normal', and I am more positive about the future", he stated with passion, and punched his fist into his hand with a grin.

Putting on a brave face: "I think feeling ill is an indication of weakness. It's like the runt in a litter of dogs, and the weak one doesn't survive". The nurse flicked through the 
patient's paperwork, tracing her finger under each word, 'Anterior STEMI, CABG. No

complications.' She looked up from the clinical notes and smiled at the balding man sat opposite. He shifted uncomfortably in his chair and coughed. "Hello Mr Taylor, I'm Catherine one of the cardiac nurses, is it okay if I call you by your first name?”, the nurse relaxed back into her seat and crossed her legs, smiling warmly. Derek nodded, grunting a quiet and abrupt, "yes". His face looked ashen and sickly. He squinted and looked away. "Okay, so you had a coronary artery bypass graft about 6 weeks ago, how is everything going? How are you?" Catherine beamed. Derek's mouth was set in a hard, thin line. He nodded again and mumbled, "yeah, okay." The nurse paused, waiting for any elaboration. But the patient sat sternly, his despondent expression unmoving. "So, do you have a good understanding of what happened in hospital, or would you like me to go over anything?" she asked, re-crossing her legs and scribbling Derek's name on top of a clinical card, ready to take notes. Derek shuffled uneasily, "No, I know. I had a heart attack", he said bluntly, his arms crossed securely across his chest. "And how are you feeling?", the nurse probed again. "Yeah, fine", he reiterated, a bit louder this time with a slightly aggressive undertone. "And you are not experiencing any symptoms, like chest tightness?" Catherine confirmed, still smiling warmly despite Derek's cutting remarks. "Really, I'm fine. No pains or anything", his eyebrows furrowed, and his mouth twitched. The nurse radiated calm kindness, but this didn't break through Derek's icy demeanour. She could see the cracks of emotion forming in the lines of his face, but Derek attempted to retain a poker face barrier, he didn't want to give anything away. Catherine sighed, and moved on to talking about the cardiac rehab sessions.

Later. "God that was hard work!" Catherine shared, a sense of relief that Derek's first assessment was over. The other nurse smiled and clapped her on the back, "a bit difficult was he?" she mused. "He was just so closed! He seemed almost rude and aggressive, he had such a bad attitude. But I think it's really because of his insecurities and his fear; you know people don't know what to expect. He's probably got a lot on his mind. I could see him trying to hold back tears at one point", Catherine explained. The other nurse uttered a barely audible "ahum?", giving her 
full attention. "But no matter how hard I tried to get him to open-up and talk to me, he just sat there and was really blunt. I felt like he had a lot he needed to get off his chest, but he just bottled it up." Catherine grabbed his clinical card and scribbled a note on the back, 'anxious/depressed?' "I think we will need to keep an eye on him", Catherine suggested. "I wonder if he is in denial?" she continued. "I see it quite a lot; it's like the grieving process after a heart attack. At the beginning they're often in denial - 'this hasn't happened to me' - and then they start going through the whole, 'I can accept it' stage, and then they're sad about it, and then they come to the, 'I have to deal with it' stage." The other nurse sighed and looked to the ceiling, thinking, "yeah could be. But he also seems quite like some of the other guys we've seen here, you know the ones that have difficulty with like a change of roles or identity in the household. You know, they are used to being the strong alpha male figure and then they become ill and have to take things easy in their recovery and perhaps stay off work for a bit, so their role changes." Catherine transferred her weight to the other foot and stroked her chin, "yeah, and I had a guy in CCU [coronary care unit] and the thing that really stood out for me was the fact that he felt like everyone knew what had happened to him; he thought people he passed in the street were thinking 'well, he's had a heart attack'. He felt like he had a label on him, and he felt uncomfortable about that," Catherine reminisced. "So, I just tried to talk to him and go through the psychological issues associated with having an MI [myocardial infarction] and how to deal with it. And he didn't need any referral or anything, but I think just talking about it and just allowing him the space to freely talk about how he was feeling and listening to other people's experiences. But this guy tonight wouldn't talk!”

Four weeks later. The volunteer paced quietly into the gym and stood reassuringly at the end of the line of patients. They were all doing slow toe taps in front, warming up before the circuits. The physio stood tall in front, directing their movements. Everyone was surprisingly synchronised. "And now we will move into toe taps out to the side, starting to bring in the dancing moves!" the physio gleamed. The volunteer, June, suddenly erupted into a jig, flinging her hands from side to side. The room broke into laughter. June had been through cardiac rehab herself and 
wanted to give something back to the service. She smiled broadly, and started chatting quietly to the patient next to her, reassuring and making them feel welcome. At the other end of the line stood Derek. This was his second session, but he was still very quiet and withdrawn. Tentatively copying the physio, he peered nervously down to his feet. His face was sunken and glum.

Throughout his first session he had avoided eye contact and remained silent, dodging conversation with any of the other patients. His relentless scowl didn't help; it pushed people away, like he was surrounded with his own personal barbed wire fence. The nurse attempted to breach the barrier, “Derek, hello, we haven't seen you for a while?" It had been about 4 weeks since his first session. "I've been in hospital again; I've been crap!" he announced. The nurse stepped back, slightly surprised that Derek had said more than a grunt. He stepped from side to side and looked at the wall, as if trying to compose himself in preparation to speak, "well I had a bad cold and then I started getting sort of chest pains and feeling really down, so I panicked and thought it was happening to me again. But they did a blood test and everything was fine." The nurse nodded, "ah I see." Derek resumed, "then I also had numbness too, on this side", he pointed to the top left-hand side of his chest and grimaced. "But I've been to see the GP and the consultant, they said it's normal after being opened-up to have nerve damage and numbness", he spoke quickly. The nurse agreed, "yes that's right, it's normal to feel a bit of tingling and numbness," and she listened on. "They said I have probably been doing too much too soon after my surgery. Not here, but at home; I've gone back too quickly to things." Not being able to get a word in, the nurse let him continue with his unrestrained story; he was beginning to open up "they said I was just panicking, feeling anxious, and worried, they said I've got nothing to worry about", he repeated. "I fell in the bath; can you believe that?!... My arms are so weak now, and I forgot, and when I went to lower myself into the bath, my arms buckled and I smashed into the bath. Luckily, I didn't hit my head or anything", he grimaced. It was as though Derek had just realized the full extent of what had happened to him. He appeared to be struggling with his sense of self and a perceived loss of control. "Your body has been through a lot and it's going to take a while to fully recover", the 
nurse tried to reassure him. He cut her off rudely, "yes, yes that's what the consultant said too, well now you know why I haven't been here", and he turned to walk away, shutting down the conversation and raising the barbed wire fence again.

The next session didn't show any improvement in Derek's mental state. He suddenly burst through the door into the waiting room, extremely hurried and flustered, like a whirlwind of pent up chaos. Red faced, he sprawled out onto a seat, legs splayed out and head hanging back. Concerned the nurse approached him, “you okay Derek?” He sat up and sighed loudly, “I'm knackered. Work are being shit!” he blurted. Derek looked tired, his eyes were squinting, and he shifted uncomfortably in his chair. "I am behind on work. They are just shit! I have so much to do, and I feel pressured to get it done. I started early and have only just finished with no lunch!” He appeared angry and fed up. Luckily the waiting room was quiet with only two volunteers present, so the nurse could dedicate time to talk with Derek. She sat next to him and said with a soothing voice, "is there any way you could have a chat with work and get them to reduce your workload at this early stage in your recovery?" Derek looked wired and flustered, he rummaged in a carrier bag and pulled out a drink. He sipped it. 'I'll try but it's just not me, I have always run that warehouse with no problem. I think feeling ill is an indication of weakness. It's like the runt in a litter of dogs, and the weak one doesn't survive. I don't want to advertise that at work." Alarmed he hadn't eaten anything all day the nurse persuaded Derek to go home, "perhaps you should give the exercise session a miss tonight as you haven't eaten all day?" the nurse had an air of authority and a motherly tone. Derek averted his gaze and moved around in his chair, unable to settle. "Okay", he moaned, and unscrewed his water bottle taking another sip. He seemed embarrassed, keeping his head down. Later the volunteer, June, approached the nurse, "I think Derek's holding back; he's not telling you the whole story. He's very closed." The nurse nodded, "yeah I think he is embarrassed to say anything." June sighed, “yeah he's a man isn't he?! Got to do the macho thing. Some get embarrassed about getting emotional. You know, they don't like to look soppy do they?!" she half laughed, but seemed concerned. 
Catherine flicked through the clinical cards and started removing names of patients that hadn't attended the sessions in a while. She stopped on Derek's card and exhaled loudly. He hadn't been to the sessions for a month now, and they had left a voicemail 2 weeks ago. Catherine picked up the phone and dialed. The phone rang, and Catherine was hopeful Derek would pick up. This number is unavailable, please leave a message after the tone.

An inspiration: "It's having that sense of humour and positive mind set". The old lady clutched her walking stick and shuffled. The wrinkles on her tired face scrunched up as she took a slow painful step forward. Getting from the door to a seat was a monumental effort. She winced with every step, battling against the discomfort surging through her crippled body. Finally reaching her goal, she puffed, red faced, and crumpled into a seated position. Her hand loosened around the stick. She grimaced and sighed. Walking 10 meters was like reaching the top of Everest. "Hello Mary, it's lovely to see you again", the nurse swooped over smiling. The nurse, Sally, works in the coronary care unit (CCU) at the hospital where Mary received treatment for an MI. Mary glanced up and managed a smile through clenched teeth; her leg was still throbbing from the walk over. Sally sat close by and shuffled Mary's paperwork, preparing for the preassessment. Mary had an extensive cardiac history and a range of co-morbidities. The nurse traced a finger down Mary's past medical history: $M I x$ 2, PCI, CABG, type 2 diabetes mellitus, bilateral knee replacement, osteoarthritis, transient ischaemic attack. Mary shifted uncomfortably, “I can’t believe it's been 6 weeks since I was in hospital", she expressed. "I know!", Sally mirrored, "and how are things at this moment?” Mary exhaled heavily and her lip trembled. Her face suddenly transformed, her feelings gushing out all at once 'I'm in pain, lots of pain, and it's like I just don't want to do anything. I can't be bothered, you know, I can't be bothered to do anything. I can't even be bothered to eat. I can't sleep, and I just want to sit on the sofa." Tears welled up and pooled in her eyes. Sensing Mary's distress, Sally shuffled forward and grasped her hands warmly. Mary bowed her head and began to sob. Large tears rolled over her wrinkles and dripped into her lap. 'I'm really sorry I don't mean to break down, but I'm just going through a lot at this 
moment!" Sally patted Mary's hands, "that's fine, we are here to support you". Mary sniffed and wiped her tears away with her sleeve, "all I do is stay in the house all day! My blood glucose levels are all over the place, and whenever I try to move I get shooting pains in my legs", she paused and breathed, "and I sit there and look around the house and there's dust everywhere! I can see the dust over the sides and the ornaments, and I can't even get up and clean it. I can't do any house work because I am too breathless", she explained in frustration. Sally nodded empathetically and listened. Mary had a lot of bottled up emotions that she wanted to vent, and Sally was her selected outlet. She sat strongly soaking up Mary’s grief, pain, and aggravation.

One month later. June, a volunteer at the cardiac rehab programme, stood listening intently to the nurse's instructions, "Mary is here again tonight, June are you okay to stick with her again, just to give her extra reassurance?" The nurse directed the volunteers and gave the staff an overview of the patients that were attending. "Yes, no problem", June smiled and made her way into the gym to join Mary. She was stood holding the back of a chair slowly marching on the spot. “Good evening Mary!" the volunteer beamed. "Hello June", Mary panted. "How are you getting on tonight?" Mary paused for breath. "I am just taking my time. It feels like I am changing the way I move, like I am restricted, and need to constantly adapt the way I move to compensate for the different pains," she lifted her knee and winced, "It's like someone has hijacked my body!" June nodded, "yeah I felt the same when I was going through this. It's like treading on egg shells after you've had a heart attack. I just wasn't sure how much I could do, you know, you don't want to break the shells. But coming here I found that I could do a lot more than I thought," June shared positively. "Yeah exactly, and I am definitely doing a lot more than I was. I'm not going to let it beat me; I don't want to be a cardiac cripple! Emotionally it's very tiring, because the other pains I have are constant. But it's all about having a sense of humour!" Mary grinned, "having raised 4 children you learn to cope well with stress. I try to put a positive spin on things and make a laugh and joke of it." June smiled and chortled, "blimey, yeah 4 children! I had trouble with 1!" Mary giggled. She had stopped marching now and was wobbling to pick up her stick. "I'll get that!" 
June swooped down and scooped it up. "You know, I didn't realize how miserable I was before coming here. I had to try very hard not to bite someone's head off; my temper became short. But I didn't give up; I think anybody else would have given up a very long time ago. I keep wrestling with my mind so that it doesn't get me down. I am getting to know myself better”, Mary explained, pausing between exercises. "Good for you, and that determination will help so much!" June lauded. Still grasping Mary's stick, June suddenly broke into a Charleston dance. They both held their heads back and laughed loudly.

The following week, Katie the physio was setting up the gym for the rehab session, when she heard a shuffling behind her. It was Mary. The taxi had dropped her off behind the hospital, and she had just trudged up the small hill and through the back door into the gym. "Hello Mary!" Katie smiled. "Uh", Mary grunted, lumbering across the gym. There seemed to be no fluidity in the way she walked. Her arms stuck to her sides and she waddled, much like a duck. Her face was red, and she was somewhat short of breath, leaning precariously on her stick. The physio followed her into the waiting room where she sunk into a chair and sighed, "okay I'm ready for sprinting now!", she joked. Katie giggled, "brilliant because we have lots of sprinting tonight and, also, a lot of press ups!" she teased. Mary smiled and tutted, rolling her eyes. Katie sat next to Mary, "so how are things?" They had built a strong therapeutic relationship and it allowed their communication to flow. Trusting the physio, Mary revealed her progress and confided in her, "I'm really enjoying myself here, it's so friendly. Of course, I am still in pain", she frowned and tapped her knees, "but I think I always will be, I've accepted it." Katie nodded and hummed. "But it's that mental frame of mind. And I know the way I try and motivate my mind, and do things, and it's one of try to be positive, it’s very easy to be negative". “Absolutely, I wish I was more like you!” Katie smiled. Mary laughed and clapped Katie on the back. "Well, you know, it's all about the atmosphere here, it's encouraging, it's listening, and moulding to the individual and it helps you feel more involved and motivated", Mary praised. She paused and sucked on her teeth. "The recovery process after a heart attack is both very painful and quite long, um, and it has dragged me down, it is quite 
demoralising", Mary shared. "And you can sit watching the TV and you can just burst into tears! That is eating away at me, like now with my pain, I know that it is going to be uncomfortable, and think 'there's no point in going to do anything'. You don't want to go and intentionally hurt yourself", she cringed. Katie nodded and listened shuffling closer on her chair. "It's just been a lot of closed doors, and you know it's no good knocking on any of them, because you don't get answers; they are not able to do anything. But coming here gives reassurance that this isn't it, life isn't over just because you've had a cardiac event, you're here to put us back together again like humpty dumpty, and pack us off down the road to get on with life again”, Mary made gestures with her hands, moving her fingers as if gluing pieces of shell together. "Even though I am still in pain, I am doing things with slightly more vigour. Slightly more drive and ambition, rather than sitting back, and thinking 'oh this is it! Life is over for me!' You know?". The physio nodded her head enthusiastically in agreement, captivated by Mary's story. “And when I hear somebody else here say, 'oh well my dad had 3 bypass operations and he eventually died when he was 86 !', it's very motivational to me. I'm not done yet!" Mary winked.

Another exercise session was coming to an end. The physio wrapped up the cool down, "and now take a deep breath and circle your arms to the ceiling", she stretched up, "and breathing out, relax", everyone took a deep sigh letting their hands fall to their sides. "Well done everyone!" Katie exclaimed smiling. Suddenly the nurse ran into the centre of the room clutching a certificate. "One moment, just before you go. We have someone graduating tonight! This lady has done extremely well and is a true inspiration, we will miss her! Please give a round of applause to Mary for finishing cardiac rehab and for all of her efforts!" The room burst into applause, as the nurse handed Mary her certificate. Mary grinned and bowed her head. Her eyes welled and she swallowed, overwhelmed by everyone's cheering. The clapping died down. Mary coughed and spoke softly, "Thank you so much. I've really enjoyed it here; you are all like friends. As soon as you walk through that door everyone makes you feel so welcome. It's hard to leave!' Despite all her difficulties, and her struggling body, Mary was still smiling. 


\section{Discussion}

The aim of this study was to explore the emotions and behaviours underpinning the interpersonal dynamics of a UK CR setting. Three composite narratives illustrated the emotional intensity of recovering from a cardiac event, and highlighted the value of CR to aid patients with reskilling and emotional support. Being diagnosed with CVD elicited a range of emotions (e.g., anxiety, shock, fear, despair) associated with preoccupations with bodily states, social isolation, and challenges to re-learn individual identity. Rather than a 'tick box' 'clinical' activity, staff provided compassionate care and fostered a positive, and encouraging atmosphere. Essential to patient-centred care was the staff's ability to understand others and to subsequently tailor their own behaviours and emotions to provide the most effective rehabilitation pathway for each patient. Nevertheless, some patients required extra psychological support, and referral to counselling, highlighting the need for improved streamlining of psychosocial services and expertise.

This study resonates with and extends previous ethnographic findings of recovering and living with chronic CVD (e.g., Wheatley, 2006). In line with Wheatley's description of reskilling, patients appeared to transform personal identity and understand bodily states, through a process of coping with shifting bodily symptoms and the correspondent emotions of having heart disease.

The current findings illustrated that a common source of anxiety following a cardiac event was the fear of a subsequent heart attack, and a preoccupation with the body that could lead to 'cardiophobia' and 'kinesiophobia'. For example, George's narrative highlights the experience of fear in response to an increasing heart rate, and a renewed awareness of sensations in the body, which initially restricted recovery and exercise behaviours. To elaborate, 'cardiophobia' is anxiety in relation to feelings of vulnerability, loss of trust in the body, mysteriousness of bodily sensations, and intensification of symptoms (see also Eifert, 1992). Similarly, 'kinesiophobia' is an excessive fear of movement, which has been shown to negatively influence rehabilitation outcomes, such as exercise uptake and adherence (Bäck, Öberg, \& Krevers, 2017; Kocjan \& Knapik, 2014). Consistent with Wheatley, current results showed that some patients considered 
anxiety to be more central to suffering than cardiac pathology. In response to this suffering, CR appeared to help processes of reskilling, allowing patients to reflexively acknowledge and adapt their responses to bodily and emotional states in an environment that enhanced patients' embodied knowledge. Heggdal (2013) defined four key phases to embodiment, including: 1) uncertainty (denying and escaping the sick body); 2) losing life space (grieving and anger); 3) listening and understanding the body's signs (strengthening hope), and; 4) integrating embodied knowledge (new possibilities for well-being and health). For instance, Mary's narrative showcases the possibilities for embodied knowledge despite experiencing multiple morbidities, illustrating her acceptance and management of pain, and living with 'more drive and ambition' rather than thinking that her 'life is over'. Nevertheless, the narratives reported here highlighted 'bodyknowledging' as an ongoing process, with each patient's perspectives fluctuating, moving in and out of Heggdal's four phases. Continuing symptoms (e.g., breathlessness, pain), and medicinal side effects (e.g., digestive issues, fatigue) persistently challenged patients' body perceptions and, subsequently, their emotions, emphasizing the ongoing nature of reskilling following a cardiac event (e.g., Wheatley, 2006).

Given the range of emotions associated with cardiac disease, an integral characteristic of the CR setting was a positive, supporting, and inclusive milieu that encouraged emotional disclosure. Psychological adjustment to illness requires cognitive and emotional processing of illness related thoughts and feelings (Cordova, Ruzek, Benoit \& Brunet, 2003). Hence, an environment that fostered emotional disclosure promoted the contemplation and integration of illness thoughts and feelings to reach emotional resolution (e.g., Cullen et al., 2018). Patients shared their illness stories with staff, volunteers and other patients, disclosing their emotions to improve recovery and reshape their experiences of illness (see Frank, 2013). Several important factors and processes created a rehabilitative environment that nurtured emotional disclosure, including authentic positive emotions, emotional intelligence, and emotion contagion. Consistent with views in positive psychology (see Seligman \& Csikszentmihalyi, 2000) findings illustrated 
that positive emotions of staff and volunteers created positive relationships that rippled through the CR setting at a collective level. Staff and volunteers displayed authentic positive emotions, and through processes of emotion contagion, these emotions flowed from one person to another (e.g., Troth, Lawrence, Jordan \& Ashkanasy, 2017). This positive atmosphere allowed conversations to flow, opening dialogue between staff, patients and volunteers. Importantly, a social environment that promotes disclosure can validate emotional expression, and subsequently support active contemplation of illness, facilitating processing, decreasing distress, and increasing well-being (see Lepore, 2001). Nevertheless, patients differed in their desire, comfort, needs, and skill in talking about their illness experience.

Emotional disclosure is an interactive process, thus social constraints and certain styles of disclosure (e.g., criticism, defensiveness, contempt, and withdrawal) can impair cognitiveemotional processing and thwart emotional resolution (e.g., de Ridder et al., 2008). In the presented narratives, some patients exhibited emotional suppression, in which they inhibited emotion expressive behaviour, hiding true felt emotions through trying to maintain a neutral expression (see Gross, 2015). Existing literature pinpoints emotional suppression as a maladaptive regulation strategy hindering social functioning (e.g. Butler et al., 2003), impeding cardiac surgery recovery (Messerli-Burgy et al., 2012), and increasing emotional distress in rehabilitative settings (e.g., Iwamitsu et al., 2005). During the development of our themes and observations, we noticed that males appeared more likely to suppress illness-related thoughts and emotions to protect masculinity and restore social dignity within fields of activity, including family, friendships, and employment (e.g., Angus et al., 2018). Subsequently, Derek's narrative illuminates the avoidance of emotional expression in male patients, supporting previous rehabilitation and health research indicating an association between masculinity and reduced help-seeking behaviours (e.g., Galdas, Cheater, \& Marshall, 2007), and increased stigma towards mental illness (e.g., O’Brien, Hart, \& Hunt, 2007). Results indicated several maladaptive consequences of social inhibition, including increased stress at work, poor nutrition, overexertion, isolation, depressive symptoms and drop out 
from CR (see also Lepore \& Helgeson, 1998). Therefore, an important component of the reskilling process following a cardiac event is the interpretation and interactional efforts to remake one's social world (cf. Wheatley, 2006). Moreover, building networks of social support in CR was integral to promoting emotional disclosure and alleviating suffering.

In this study, a fundamental aspect promoting enhanced social support in CR was the emotional intelligence of health professionals. Emotional intelligence refers to, the abilities to understand and regulate one's own emotions, and the emotions of others, and to use this understanding to guide one's thinking and actions (Salovey \& Mayer, 1990). Conversations with staff, and observations in CR demonstrated the staff's abilities to pick up on patient emotions, and adapt their behaviour in response to enhance patient care. Subsequently, the interactions depicted in the narratives above highlight emotional intelligent behaviour. For instance, in Derek's narrative the nurse picked up on Derek suppressing emotions, and reappraised his rude expressions and aggressive comments as fear and anxiety. Consequently, the nurse remained empathetic and calm, and pinpointed Derek as someone 'to keep an eye on'. These findings are in line with a review by Nightingale, Spiby, Sheen and Slade (2018), who found that developing emotional intelligence in nurses positively impacted upon physical and emotional caring behaviours. Furthermore, emotional intelligence has been shown to increase effective communication (e.g., Lewis, Neville \& Ashkanasy, 2017), with subsequent importance in the development of therapeutic relationships that can provide a gateway for effective care (see Weeger \& Farin, 2016). However, despite a policy for open communication in $\mathrm{CR}$, individuals with interactional difficulties, or those significantly marginalized by their illness, might benefit from referral to counselling services, or the application of interventions in practice, such as positive psychotherapy (e.g., Cullen et al., 2018). Nurses are often time-constrained, and have difficulties to provide psychological care within their existing workloads (e.g., Turner et al., 2017). Considering these resource constraints, brief psychological interventions and referral to IAPT services might be more appealing to prevent barriers to implementation (e.g., Fernandes, McIntyre, Coelho, Prata, \& Maciel, 2017). In 
accordance with current findings, a promising psychological intervention that is not labor intensive for CR staff, could include expressive emotional writing (e.g., Zakowski, Ramati, Morton, Johnson, \& Flanigan, 2004) and the use of narrative for pedagogical value in an applied setting (e.g., Smith \& Sparkes, 2009). Future research may wish to consider the value of illness stories to promote patient's emotional disclosure and enhanced cognitive-emotional processing (de Ridder et al., 2008; Frank, 2013).

\section{Conclusion}

This research extends our understanding of the emotional and behavioral underpinnings of interpersonal dynamics in a UK CR setting. Ethnographic creative non-fiction provided in depth composite narratives that highlighted the significant impact of a cardiac event on emotional wellbeing, and the importance of CR to support patient's reskilling. Several issues were raised in this study, including: 1) the maladaptive consequences of emotion suppression on recovery; 2) the need for a positive rehabilitative environment to promote emotional disclosure, and; 3) the potential use of narrative medicine to facilitate cognitive-emotional processing and psychological adjustment to CVD.

\section{Acknowledgements}

We would like to thank all the staff, volunteers and patients for their time participating in this study, and for sharing their stories.

\section{Disclosure statement}

In accordance with Taylor \& Francis policy and my ethical obligation as a researcher, I, XXX, am reporting that I am an employee of the NHS cardiac rehabilitation service, a company that may be affected by the research reported in the enclosed paper. I have disclosed those interests fully to Taylor \& Francis, and I have in place an approved plan for managing any potential conflicts arising from that involvement. XXX declares that he has no conflict of interest. XXX declares that he has no conflict of interest.

\section{References}

Anderson, L., Oldridge, N., Thompson, D. R., Zwisler, A-D., Rees, K., Martin, N., \& Taylor, R. S. (2016). Exercise-based cardiac rehabilitation for coronary heart disease: Cochrane 
systematic review and meta-analysis. Journal of the American College of Cardiology, 67, DOI: $10.1016 /$ j.jacc.2015.10.044

Angus, J. E., Dale, C. M., Nielsen, L. S., Kramer-Kile, M., Lapum, J., Pritlove, C., ... \& Clark, A. (2018). Gender matters in cardiac rehabilitation and diabetes: Using Bourdieu's concepts. Social Science and Medicine, 200, 44-51.

Atkinson, P., \& Pugsley, L. (2005). Making sense of ethnography and medical education. Medical Education, 39, 228-234.

Bäck, M., Öberg, B., \& Krevers, B. (2017). Important aspects in relation to patients' attendance at exercise-based cardiac rehabilitation- facilitators, barriers and physiotherapist's role: a qualitative study. BioMed Central Cardiovascular Disorders, 17, 1-10.

Bedi, G., \& Brown, S. L. (2005). Optimisim, coping style and emotional well-being in cardiac patients. British Journal of Health Psychology, 10, doi.org/10.1348/135910704X15266

British Association for Cardiovascular Prevention \& Rehabilitation (2017). Core competences for the physical activity and exercise component for prevention and cardiovascular rehabilitation services. Retrieved from website: https://www.bacpr.com/pages/site_search.asp?newstitle=core+competences\&Submit2=Sea rch

British Heart Foundation (2018). CVD statistics- BHF UK factsheet. Retrieved from website: https://www.bhf.org.uk/research/heart-statistics

British Heart Foundation (2017). The national audit of cardiac rehabilitation: Annual statistical report 2017. Retrieved from website: https://www.bhf.org.uk/publications/statistics/national-audit-of-cardiac-rehabilitationannual-statistical-report-2017

Braun, V., \& Clarke, V. (2006). Using thematic analysis in psychology. Qualitative Research in Psychology, 3, 77-101.

Butler, E. A., Egloff, B., Wilhelm, F. H., Smith, N. C., Erickson, E. A., \& Gross, J. J. (2003). The 
social consequences of expressive suppression. Emotion, 3, 48-67.

Byrne, R. A., Stone, G. W., Ormiston, J., \& Kastrati, A. (2017). Percutaneous coronary intervention 1: Coronary balloon angioplasty, stents, and scaffolds. Lancet, 390, 781-792.

Cavallerio, F., Wadey, R., \& Wagstaff, C. R. D. (2016). Understanding overuse injuries in rhythmic gymnastics: A 12-month ethnographic study. Psychology of Sport \& Exercise, 25, 100-109.

Charon, R. (2006). Narrative Medicine: Honoring the stories of illness. New York, USA: Oxford University Press.

Cordova, M. J., Ruzek, J. I., Benoit, M., \& Brunet, A. (2003). Promotion of emotional disclosure following illness and injury: A brief intervention for medical patients and their families. Cognitive and Behavioral Practice, 10, 358-371.

Crossley, M. L., Nicolson, P., \& Owens, G. (2001). Do we need to rethink health psychology? Commentaries on Crossley's "Do we need to rethink health psychology?" Psychology, Health \& Medicine, 6, 243-265.

Cullen, B., Pownall, J., Cummings, J., Baylan, S., Broomfield, N., Haig, C., ... \& Evans, J. J. (2018). Positive psychotherapy in ABI rehab (PoPsTAR): A pilot randomised controlled trial. Neuropsychological Rehabilitation, 28, 17-33.

Dalal, H. M., Doherty, P., \& Taylor, R. S. (2015). Cardiac rehabilitation: Clinical review. The British Medical Journal, 351, doi: 10.1136/bmj.h5000

de Ridder, D., Geenen, R., Kuijer, R., \& van Middendorp, H. (2008). Psychological adjustment to chronic disease. Lancet, 372, 246-255.

Eifert, G. H. (1992). Cardiophobia: A paradigmatic behavioural model of heart-focused anxiety and non-anginal chest pain. Behaviour Research and Therapy, 30, 329-345.

Fernandes, A. C., McIntyre, T., Coelho, R., Prata, J., \& Maciel, M. J. (2017). Brief psychological intervention in phase I of cardiac rehabilitation after acute coronary syndrome. Revista Portuguesa de Cardiologia, 36, 641-649. 
Frank, A. W. (2013). The wounded storyteller: Body, illness, and ethics $\left(2^{\text {nd }}\right.$ Ed). Chicago, USA: The University of Chicago Press.

Galdas, P., Cheater, F., \& Marshall, P. (2007). What is the role of masculinity in white and South Asian men's decisions to seek medical help for cardiac chest pain? Journal of Health Services Research \& Policy, 12, 223-229.

Gilmore, S., \& Kenny, K. (2015). Work-worlds colliding: Self-reflexivity, power and emotion in organizational ethnography. Human Relations, 68, 55-78.

Gross, J. J. (2015). The extended process model of emotion regulation: Elaborations, applications, and future directions. Psychological Inquiry, 26, 130-137.

Hammersley, M., \& Atkinson, P. (2007). Ethnography: Principles in Practice $\left(3^{\text {rd }}\right.$ Ed). Taylor \& Francis e-Library.

Heggdal, K. (2013). Utilizing bodily knowledge in patients with chronic illness in the promotion of their health: A grounded theory study. Californian Journal of Health Promotion, 11, 6273.

Hings, R. F., Wagstaff, C. R. D., Anderson, V., Gilmore, S., \& Thelwell, R. C. (2018). Professional challenges in elite sports medicine and science: Composite vignettes of practitioner emotional labor. Psychology of Sport \& Exercise, 35, 66-73.

Hosseini, S. H., Ghaemian, A., Mehdizadeh, E., \& Ashraf, H. (2014). Levels of anxiety and depression as predictors of mortality following myocardial infarction: A 5-year follow-up. Cardiology Journal, 21, 370-377.

Iwamitsu, Y., Shimoda, K., Abe, H., Tani, T., Okawa, M., \& Buck, R. (2005). Anxiety, emotional suppression, and psychological distress before and after breast cancer diagnosis. Psychosomatics, 46, 19-24.

Kocjan, J., \& Knapik, A. (2014). Barriers of physical activity (kinesiophobia) in patients subjected to cardiac rehabilitation. Baltic Journal of Health and Physical Activity, 6, 291-297.

Kraine, V., \& Baird, S. M. (2005). Using ethnography in applied sport psychology. Journal of 
Applied Sport Psychology, 17, 87-107.

Lepore, S. J. (2001). A social-cognitive processing model of emotional adjustment to cancer. In A. Baum \& B. Andersen (Eds.), Psychosocial interventions for cancer (pp. 99-118). Washington, DC: APA.

Lepore, S. J., \& Helgeson, V. S. (1998). Social constraints, intrusive thoughts, and mental health after prostate cancer. Journal of Social and Clinical Psychology, 17, 89-106.

Lewis, G. M., Neville, C., \& Ashkanasy, N. M. (2017). Emotional intelligence and affective events in nurse education: A narrative review. Nurse Education Today, 53, 34-40.

Linden, W. (2000). Psychological treatments in cardiac rehabilitation: Review of rationales and outcomes. Journal of Psychosomatic Research, 48, 443-454.

Messerli-Burgy, N., Barth, J., Von Känel, R., Schmid, J. P., Saner, H., \& Snoj, H. (2012). Maladaptive emotion regulation is related to distressed personalities in cardiac patients. Stress \& Health, 28, 347-352.

Michie, S., O’Connor, D., Bath, J., Giles, M., \& Earll, L. (2005). Cardiac rehabilitation: The psychological changes that predict health outcome and healthy behaviour. Psychology, Health and Medicine, 10, 88-95.

National Institute for Health and Clinical Excellence. (2009). The treatment and management of depression in adults (Clinical Guideline 90). Retrieved from website: https://www.nice.org.uk/Search?q=+depression+in+adults

NHS Mental Health Task Force (2016). The five year forward view for mental health. Retrieved from website: https://www.england.nhs.uk/wp-content/uploads/2016/02/Mental-HealthTaskforce-FYFV-final.pdf

Nightingale, S., Spiby, H., Sheen, K., \& Slade, P. (2018). The impact of emotional intelligence in health care professionals on caring behaviour towards patients in clinical and long-term care settings: Findings from an integrative review. International Journal of Nursing Studies, 80, 106-117. 
O’Brien, R., Hart, G. J., \& Hunt, K. (2007) "Standing out from the herd": Men renegotiating masculinity in relation to their experience of illness. International Journal of Men's Health, 6, 178-200.

Reeves, S. A., Kuper, A., \& Hodges, B. D. (2008). Qualitative research methodologies: Ethnography. British Medical Journal, 337, doi.org/10.1136/bmj.a1020

Salovey, P., \& Mayer, J. D. (1990). Emotional intelligence. Imagination, Cognition and Personality, 9, 185-211.

Seligman, M. E. P., \& Csikszentmihalyi, M. (2000). Positive psychology: An introduction. American Psychologist, 55, 5-14.

Silk, M. (2005). Sporting Ethnography: Philosophy, Methodology \& Reflection. In D. Andrews, D. Mason, \& M. Silk (Eds.), Qualitative Methods in Sports Studies (pp. 65-103). Oxford: Berg.

Simony, C. P., Dreyer, P., Pedersen, B. D, \& Birkelund, R. (2015). Empowered to gain a new foothold in life: A study of the meaning of participating in cardiac rehabilitation to patients afflicted by a minor heart attack. International Journal of Qualitative Studies in Health and Well-Being, 1, doi: 10.3402/qhw.v10.28717

Smith, B. (2013). Sporting spinal cord injuries, social relations, and rehabilitation narratives: an ethnographic creative non-fiction of becoming disabled through sport. Sociology of Sport Journal, 30, 132-152.

Smith, B., \& McGannon, K R. (2018). Developing rigor in qualitative research: problems and opportunities within sport and exercise psychology. International Review of Sport \& Exercise Psychology, 11, 100-121.

Smith, B., McGannon, K. R., \& Williams, T. L. (2015). Ethnographic creative non-fiction: Exploring the what's, why's and how's. In G. Molnar, \& L. G. Purdy (Eds.), Ethnographies in sport and exercise research (pp. 59-74). London: Routledge.

Smith, B., \& Sparkes, A. C. (2009). Narrative inquiry in sport and exercise psychology: What can 
it mean and why might we do it? Psychology of Sport and Exercise, 10, 1-11.

Spalding, N. J., \& Phillips, T. (2007). Exploring the use of vignettes: from validity to trustworthiness. Qualitative Health Research, 17, 954-962.

Sparkes, A. C., \& Douglas, K. (2007). Making the case for poetic representations: an example in action. The Sport Psychologist, 21, 170-189.

Thombs, B. D., Bass, E. B., Ford, D. E., Stewart, K. J., Tsilidis, K. K., Patel, U., ... \& Ziegelstein, R. C. (2006). Prevalence of depression in survivors of acute myocardial infarction: Review of the evidence. Journal of General Internal Medicine, 21, 30-38.

Troth, A. C., Lawrence, S. A., Jordan, P. J., \& Ashkanasy, N. M. (2017). Interpersonal emotion regulation in the workplace: A conceptual and operational review and future research agenda. International Journal of Management Reviews, 20, doi.org/10.1111/ijmr.12144

Turner, J., \& Kelly, B. (2000). Emotional dimensions of chronic disease. The Western Journal of Medicine, 172, 124-128.

Turner, K. M., Winder, R., Campbell, J. L., Richards, D. A., Gandhi, M., Dickens, C. M., \& Richards, S. (2017). Patients' and nurses' views on providing psychological support within cardiac rehabilitation programmes: A qualitative study. British Medical Journal Open, 7, doi:10.1136/ bmjopen-2017-017510

Van Stel, H. F., Busschbach, J. J. V., Hunink, M. M. G., \& Buskens, E. (2012). Impact of secondary cardiovascular events on health status. Value in Health, 15, 175-182.

Watkins, L. L., Koch, G. G., Sherwood, A., Blumenthal, J. A., Davidson J. R. T., O’Connor, C., ... \& Sketch, M. H. (2013). Association of anxiety and depression with all-cause mortality in individuals with coronary heart disease. Journal of the American Heart Association, doi: 10.1161/JAHA.112.000068

Weeger, S., \& Farin, E. (2016). The effect of the patient-physician relationship on health-related quality of life after cardiac rehabilitation. Disability and rehabilitation, 39, 468-476.

Wheatley, E. A. (2006). Bodies at risk: An ethnography of heart disease. Aldershot, UK: Ashgate 
Publishing Ltd.

Yohannes, A. M., Doherty, P., Bundy, C., \& Yalfani, A. (2010). The long-term benefits of cardiac rehabilitation on depression, anxiety, physical activity and quality of life. Journal of Clinical Nursing, 19, doi.org/10.1111/j.1365-2702.2010.03313.x

Zakowski, S. G., Ramati, A., Morton, C., Johnson, P., \& Flanigan, R. (2004). Written emotional disclosure buffers the effects of social constraints on distress among cancer patients. Health Psychology, 23, 555-563. 